\title{
Silver Nanoparticles Mediated by Natural Extracts Recovered from Wastes and By-Products ${ }^{\dagger}$
}

\author{
Cristian Moisa ${ }^{1, *(\mathbb{D})}$, Andreea I. Lupitu ${ }^{1}(\mathbb{D})$, Adriana Csakvari ${ }^{2}$, Dana Radu ${ }^{1}$, Dorina Chambre ${ }^{1}$, \\ Lucian Copolovici $^{1}$ (D) and Dana Maria Copolovici ${ }^{1}$ (ID)
}

1 Faculty of Food Engineering, Tourism and Environmental Protection, Institute of Technical and Natural Sciences Research-Development-Innovation, "Aurel Vlaicu” University of Arad, Elena Dragoi St., Nr. 2, 310330 Arad, Romania; pag.andreea@yahoo.com (A.I.L.); poianarusca@yahoo.com (D.R.); dorinachambree@yahoo.com (D.C.); lucian.copolovici@uav.ro (L.C.); dana.copolovici@uav.ro (D.M.C.)

2 Biomedical Sciences Doctoral School, University of Oradea, University St., Nr. 1, 410087 Oradea, Romania; alex2adi4zina@yahoo.com

* Correspondence: moisa.cristian@yahoo.com

+ Presented at the 17th International Symposium "Priorities of Chemistry for a Sustainable Development" PRIOCHEM, Bucharest, Romania, 27-29 October 2021.

Keywords: green synthesis; phenolic compounds; plant wastes; silver nanoparticles

Citation: Moisa, C.; Lupitu, A.I.; Csakvari, A.; Radu, D.; Chambre, D.; Copolovici, L.; Copolovici, D.M. Silver Nanoparticles Mediated by Natural Extracts Recovered from Wastes and By-Products. Chem. Proc. 2022, 7, 7. https://doi.org/10.3390/ chemproc2022007007

Academic Editors: Mihaela Doni, Florin Oancea, Zina Vuluga and Radu Claudiu Fierăscu

Published: 28 February 2022

Publisher's Note: MDPI stays neutral with regard to jurisdictional claims in published maps and institutional affiliations.

Copyright: (C) 2022 by the authors. Licensee MDPI, Basel, Switzerland. This article is an open access article distributed under the terms and conditions of the Creative Commons Attribution (CC BY) license (https:// creativecommons.org/licenses/by/ $4.0 /)$.
Introduction: Current environmental problems demand an eco-friendlier approach to the chemical synthesis of metal nanoparticles (NPs) [1]. By using plant extracts obtained from waste materials and by-products resulting from the essential oil and textile industry, the resulting green nanoparticles represent a sustainable alternative for the classical synthetic route [2,3]. In our study, we obtained silver nanoparticles (AgNPs) by using aqueous plant extracts from Cannabis sativa, Thymus vulgaris, Lavandula angustifolia, and Origanum vulgare. The chemical composition of the extracts was determined by chromatographic and spectroscopic methods. AgNPs with less than $70 \mathrm{~nm}$ were obtained and characterized by UV-VIS, FT-IR spectroscopy, and SEM. The antioxidant activity (DPPH and ABTS assays) and the antibacterial properties against Gram-positive and Gram-negative bacteria of some of the samples were evaluated. Materials and methods: For the green NPs synthesis, the plant extracts were freshly prepared and filtered through a $0.45 \mathrm{~mm}$ PVDF, then $0.5 \mathrm{~mL}$ extract was mixed with $0.5 \mathrm{~mL} 5 \mathrm{mM}$ silver nitrate solution and $0.7 \mathrm{~mL}$ purified water. The total reaction time was $8 \mathrm{~min}$ at $90^{\circ} \mathrm{C}$. Results: The bio-reduction of silver ions was mediated by the phenolic compounds present in the aqueous extracts. This reaction was easily observed by a visual colour change from pale gold to a reddish-brown and confirmed by UV-Vis spectral analysis, with an average particle size of 35-70 nm. Nanoparticle morphology was observed using SEM and average spherical shapes were noticed. Conclusions: The preparation of silver nanoparticles was successfully performed using aqueous extracts recovered from industrial wastes and by-products. Obtaining NPs through green synthesis is a fast, easy, and eco-friendly reaction that reduced $\mathrm{Ag}^{+}$to $\mathrm{Ag}^{0}$ to spherical $\mathrm{AgNPs}$ with small average particle size.

Author Contributions: Conceptualization and study design, D.M.C.; methodology, A.C., D.R., A.I.L., C.M., D.C., L.C. and D.M.C.; validation, A.C., D.R., A.I.L., C.M., D.C., L.C. and D.M.C.; formal analysis, A.C., D.R., A.I.L., C.M., D.C., L.C. and D.M.C.; investigation, A.C., D.R., A.I.L., C.M., D.C., L.C. and D.M.C.; resources, A.C., D.R., A.I.L., C.M., D.C., L.C. and D.M.C.; data curation, D.R., D.C., L.C. and D.M.C.; writing-original draft preparation, A.C., D.R., A.I.L., C.M., D.C., L.C. and D.M.C.; writing-review and editing, D.R., D.C., L.C. and D.M.C.; visualization, A.C., D.R., A.I.L., C.M., D.C., L.C. and D.M.C.; supervision, D.R., D.C., L.C. and D.M.C.; project administration, D.M.C.; funding acquisition, C.M., L.C. and D.M.C. All authors have read and agreed to the published version of the manuscript. 
Funding: This research was funded by a grant of the Romanian Ministry of Education and Research, CNCS-UEFISCDI, project number PN-III-P1-1.1-PD-2019-0607, within PNCDI III.

Institutional Review Board Statement: Not applicable.

Informed Consent Statement: Not applicable.

Data Availability Statement: Not applicable.

Conflicts of Interest: The authors declare no conflict of interest.

\section{References}

1. Nancy, B.A.; Elumalai, K. Synthesis of Silver Nanoparticles using Pelargonium graveolens Essential Oil and Anti-Fungal Activity. Int. J. Pharm. Biol. Sci. 2019, 9, 176-185. [CrossRef]

2. Csakvari, A.C.; Moisa, C.; Radu, D.G.; Olariu, L.M.; Lupitu, A.I.; Panda, A.O.; Pop, G.; Chambre, D.; Socoliuc, V.; Copolovici, L.; et al. Green Synthesis, Characterization, and Antibacterial Properties of Silver Nanoparticles Obtained by Using Diverse Varieties of Cannabis sativa Leaf Extracts. Molecules 2021, 26, 4041. [CrossRef] [PubMed]

3. Salayová, A.; Bedlovičová, Z.; Daneu, N.; Baláž, M.; Bujňáková, Z.L.; Balážová, L.; Tkáčiková, L. Green Synthesis of Silver Nanoparticles with Antibacterial Activity Using Various Medicinal Plant Extracts: Morphology and Antibacterial Efficacy. Nanomaterials 2021, 11, 1005. [CrossRef] [PubMed] 